\title{
Experimental Study of Pipes Shape Effect on Noise Reduction
}

\author{
Dr. Muna S. Kassim \\ Assistant Professor, Al- Mustansiriyah university, College of engineering, \\ Mechanical engineering department \\ e-mail: munahdr@yahoo.com \\ Ammar Fadhil Hussein Al-Maliki \\ Assistant Lecturer, Al- Mustansiriyah university, College of engineering, Mechanical \\ engineering department \\ e-mail: eng.aa82@yahoo.com
}

\begin{abstract}
Internal combustion engine is a major source of noise pollution. These engines are used for various purposes such as, in power plants, automobiles, locomotives, and in various manufacturing machineries. The noise is caused by two reasons; the first reason is the pulses which created when the burst of high pressure gas suddenly enters the exhaust system, while the second reason is the friction of various parts of the engine where the exhaust noise is the most dominant. The limitation of the noise caused by the exhaust system is accomplished by the use of silencers and mufflers. The aim of this study is the reduction of the noise by changing its inlet and outlet pipe length and shape. Also the losses in noise for different length and shapes have been investigated experimentally. The results show that the corrugated pipe is preferable for noise reduction.
\end{abstract}

Keywords: Noise Reduction, Silencer, Muffler.

الخلاصة

ان المصدر الرئيسي للتلوث الضوضائي هو محركات الاحتراق الداخلي, حيث تستخدم هذه المحركات المئي

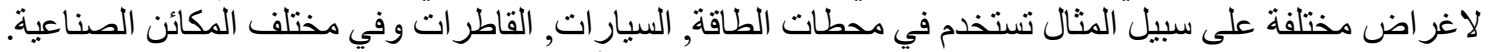

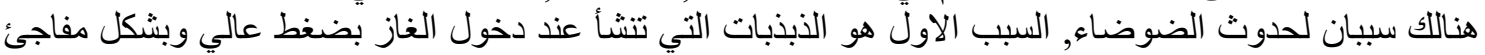

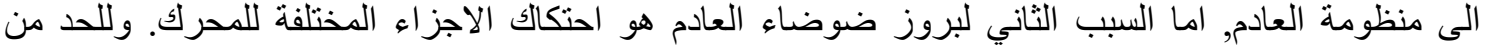

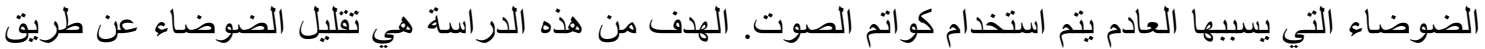

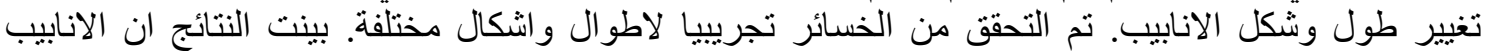

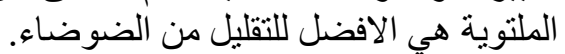




\section{Introduction}

Noise is undesirable sound. Noise pollution will soon become the third greatest menace to the human environment after air and water pollution. Since noise is a byproduct of energy conversion, there will be increasing noise as the demand for energy for transportation, power, food, and chemicals increases. In the field of control equipment, noise produced by valves has become a focal point of attention triggered in part by enforcement of the Occupational Safety and Health Act, which in most cases limits the duration of exposure to noise in industrial locations to the levels.

Mechanical noise is caused by the response of internal components within a valve to turbulent flow through the valve. Vortex shedding and turbulent flow impinging on components of the valve can induce vibration against neighboring surfaces. Noise generated by this type of vibration has a tonal characteristic. If this turbulence-induced vibration of trim parts approaches a natural frequency of the plug-stem combination, a case of resonance will exist. A resonant condition is very harmful, since it can result in fatigue failure of trim parts. Noise from mechanical vibration does not occur often in control valves, especially since the introduction of top and cage guided valves. Should it occur, steps must be taken to eliminate that resonant condition, to reduce the noise but more importantly to preclude fatigue failure. Possible cures for this type of noise include change in trim design or capacity, reduction of guide clearances, larger stem sizes, change in plug mass, and sometimes reverse of flow direction. These steps are intended to shift the natural frequency of parts and the excitation frequency away from each other. There is presently no reliable method for predicting noise generated by mechanical vibration in control valves. [1]

Silencers can be effective in reducing control valve noise provided they are installed directly downstream of the valve. However, there are several technical problems often encountered in their use. First, to be effective, they require low flow velocities, which often make them impractical, especially for use in high capacity systems. Second, the acoustic elements are not always. The use of an exhaust silencer is prompted by the need to reduce the engine exhaust noise. In most applications, the final selection of an exhaust silencer is based on a compromise between the predicted acoustical, aerodynamic, mechanical and structural performance in conjunction with the cost of the resulting system.

The silencer can be broken into three fundamental types: reactive (reflective), absorptive (dissipative), and combination reactive/absorptive. In addition to the three main silencer types, other functionality such as spark arresting, emission control, heat recovery, etc., may also be incorporated into the silencer design. [2]

The objective of this work is the reduction of the noise by changing its inlet and outlet pipe length and shape. Also to investigate the losses in noise for different length and shapes for pipes. 
Kassim et.al [3] studied the effect of inlet and outlet pipe length on noise attenuation in a muffler by using different pipe lengths for inlet and outlet (discharge) tubes with specific diameter. The results showed that the taller outlet pipe the higher noise attenuation.

Kassim [4] investigated the effect of the reactive muffler connections on noise attenuation. The experimental work includes design and fabricates a reactive muffler, spherical and cylinder shapes afterward compared the noise level for these shapes with parallel and series connection. These mufflers tested in frequency ranging (50-600 HZ). The results showed that the parallel connection is best than series connection.

Jian-dawu and Mingsian Bai [5] designed a ring silencer for reducing the noise of axial fans. The noise sources on axial fans are usually used by the fluctuating pressure distribution on the surface of fan blade. Most of the sources are near the trailing edge of blades or boundary region of blades. The ideation of reposed design is based on the principle of Helmholtz resonator for reducing the noise around the fan. The electroacoustic analogy of this design is discussed. Experimental measurement is carried out to evaluate the proposed design for reducing the axial fan noise. The result of indicated that the ring silencer achieved $(17$ decibel $(\mathrm{dB}))$ in blade passing frequency and $(10 \mathrm{~dB})$ in other broadband frequency of power spectrum level.

M.Ali T. and Y.G.Awaad [6] presented an analysis of the vibration of the exhaust gas silencer, assuming that the silencer is mainly consisting of a porous pipe of $0.042 \mathrm{~m}$ outer diameter, $0.0006 \mathrm{~m}$ thickness and $0.8 \mathrm{~m}$ length, surrounded by a cylindrical casing of $0.1325 \mathrm{~m}$ outer diameter, $0.001 \mathrm{~m}$ thickness and $0.53 \mathrm{~m}$ length, and the tail pipe is of $0.13 \mathrm{~m}$ length. The system is made up of two simple beams connected together by number of springs. The rubber fasteners (hook) which support the casing is modeled as an elastic spring. The porous pipe and the casing are divided into (30) node and (29) element along the system. The method of transfer matrices is adopted to simulate the vibration of the silencer, the dynamic characteristics, i.e. (deflection, slope, shear force, bending moment) as well as velocity, pressure and temperature are post-processed for each node.

In order to control the low frequency noise in the exhaust pipe Zhu et.al [7] used a new concept of H-Q tube based semi-active muffler device. The semi-active muffler device and bench testing system have been designed and operated. Study the finite element simulation on semi-active muffler and passive muffler has been carried on. The effect of simulation and experiment are consistent. The semi-active muffler device acts well in low frequency band, especially between $50 \mathrm{~Hz}$ and $150 \mathrm{~Hz}$. The average level of noise reduction is around $35 \mathrm{~dB}$, which is much better than passive muffler. Between $150 \mathrm{~Hz}$ and $350 \mathrm{~Hz}$, semi-active muffler has a better performance than passive muffler; above $350 \mathrm{~Hz}$, it has worse performance compared with the passive muffler.

T.Ichiyangi [8] developed research of two kinds of new multiple volume resonators, called a "variable resonance-mode type side-branch" resonator and a "multi degree of freedom type Helmholtz" resonator, are presented in the last half part. These are devised 
in order to reduce the successive several harmonics of the fixed discrete-frequency pressure pulsation such as those generated by a fixed speed hydraulic pump in a hydraulic excavator or an injection-molding machine. Unlike a conventional sidebranch or Helmholtz resonator, these can make up the desired plural resonance modes freely with a single closed-end tube configuration. It is shown that the present silencer has proven to be very successful in application to a real hydraulic excavator for reducing audible noise as well as pressure pulsation.

A reactive perforated muffler is investigated experimentally by Sumit Surve et.al [9]. For an acoustical analysis, the transmission losses which is independent of sound source of the present cross flow, the perforated muffler was analyzed. To be able to validate the numerical results, transmission loss was measured experimentally. Back pressure was obtained based on the flow field analysis and was also compared with experimental results. Numerical results have an approximate error of $20 \%$ compared to experimental results.

\section{Experimental Work}

The experimental rig used in this study consists of the system of function generator to generate sound signal with a range of frequencies $(0-1000 \mathrm{HZ})$ and used a speaker to change the electrical signals into sounds.

In this study the used duct has a length and width $(15 \mathrm{~cm})$ and $(24 \mathrm{~cm})$ respectively, with insulated inner surface at the section of connection with the loud speaker to prevent the sound reflection. It has a small pipe has a diameter $(5 \mathrm{~cm})$ and length $(20 \mathrm{~cm})$ to connect it with the muffler, figure (1) shows the duct.

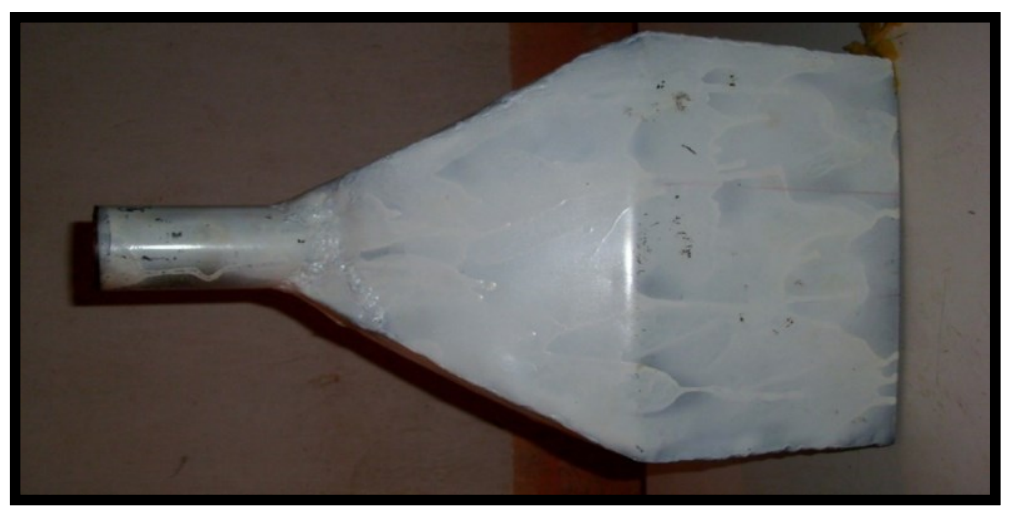

Figure (1): The duct 
Different length pipes with different shapes (continues, corrugated and spiral) were used in this study. The dimension of line pipe $(\mathrm{d}=4.8 \mathrm{~cm}, \mathrm{~L}=10 \mathrm{~cm}, 20 \mathrm{~cm}, 30 \mathrm{~cm})$ shown in figure (2), corrugated pipe which $(\mathrm{d}=4.8 \mathrm{~cm}$, pitch $=7.5, \mathrm{~L}=30,50 \mathrm{~cm}, 70 \mathrm{~cm})$ shown in figure (3) and spiral pipe which $(\mathrm{d}=4.8 \mathrm{~cm}, \mathrm{Dc}=11.5 \mathrm{~cm}, \mathrm{~L}=10 \mathrm{~cm}, 20 \mathrm{~cm}, 30$ $\mathrm{cm})$ shown in figure (4) and figure (5) .

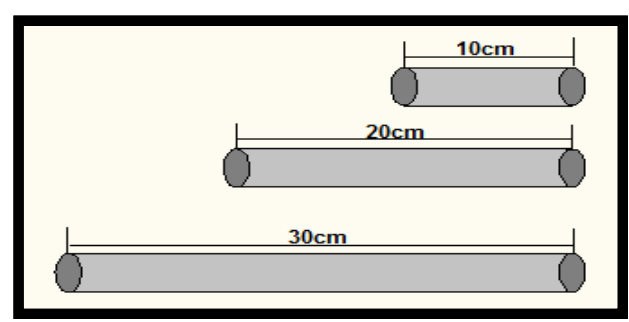

Figure (2): Continuous pipes

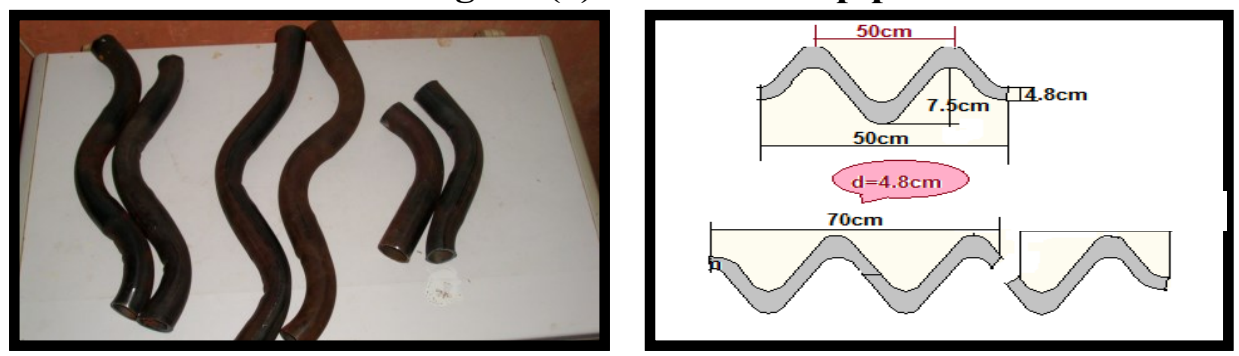

Figure (3): Corrugate pipes length of $(30 \mathrm{~cm}, 50 \mathrm{~cm}$, and $70 \mathrm{~cm})$.

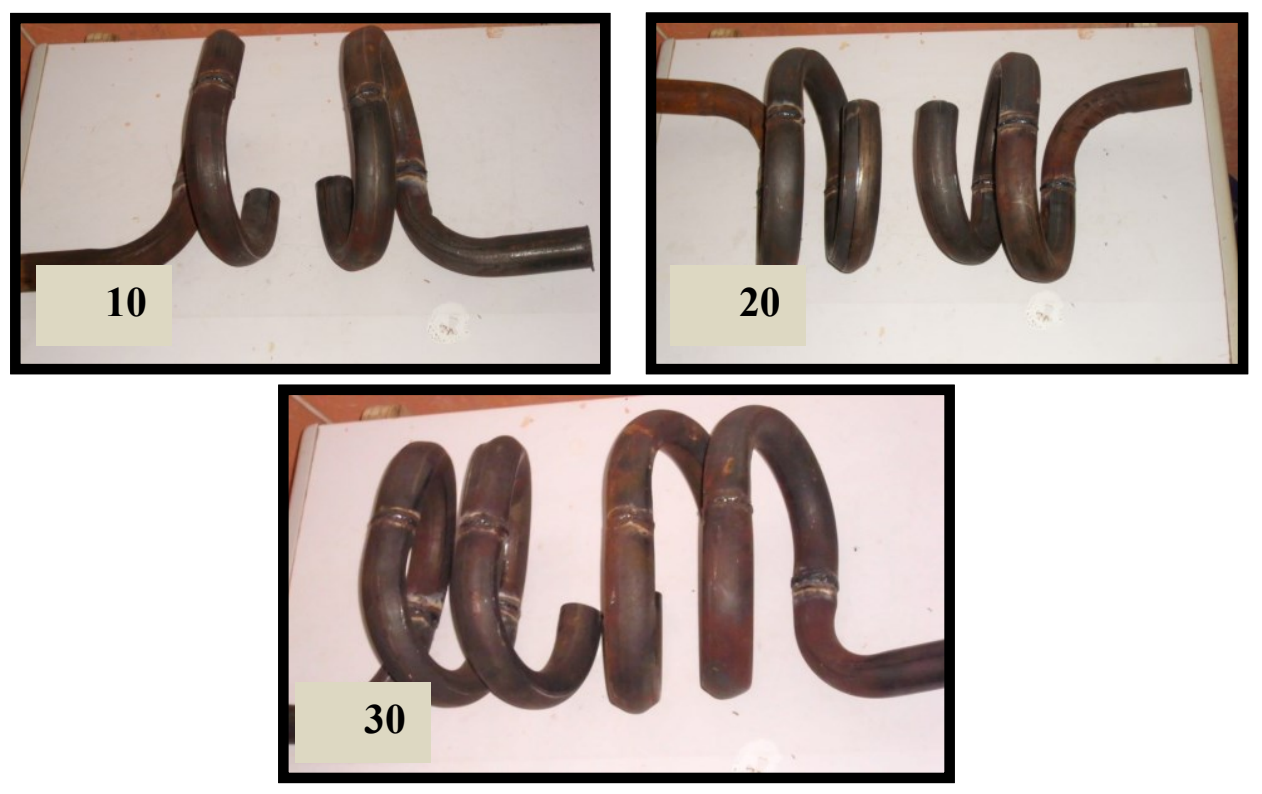

Figure (4): Spiral pipes length of $(10 \mathrm{~cm}, 20 \mathrm{~cm}$, and $30 \mathrm{~cm})$. 

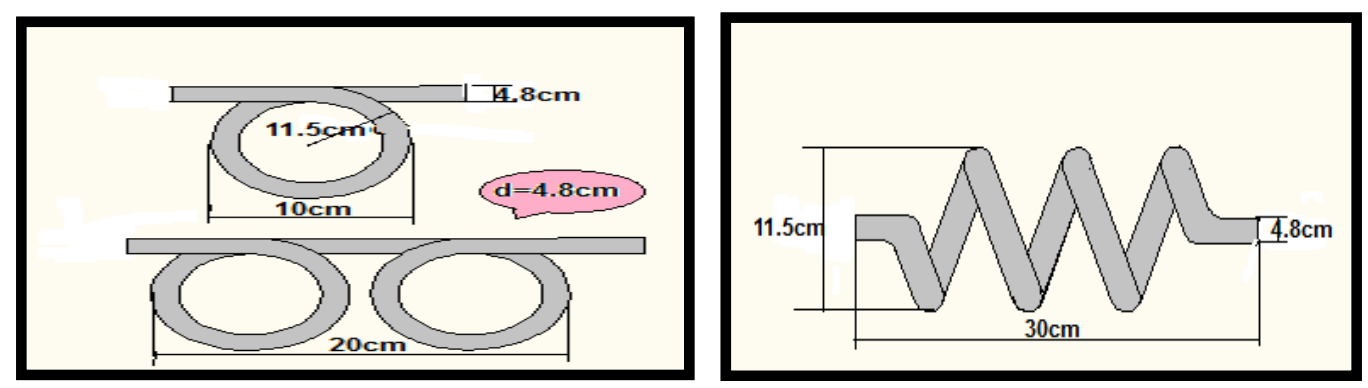

Figure (5): Schematic diagram of spiral pipes $(10 \mathrm{~cm}, 20 \mathrm{~cm}$, and $30 \mathrm{~cm})$.

In this work the muffler is manufactured with diameter of expansion chamber $(\mathrm{L}=23$ $\mathrm{cm})$ and $(\mathrm{D}=15 \mathrm{~cm})$ respectively, and diameter of its inlet and outlet pipes $(d=5 \mathrm{~cm}$, $1=9 \mathrm{~cm})$. Fig (6) shows the muffler.
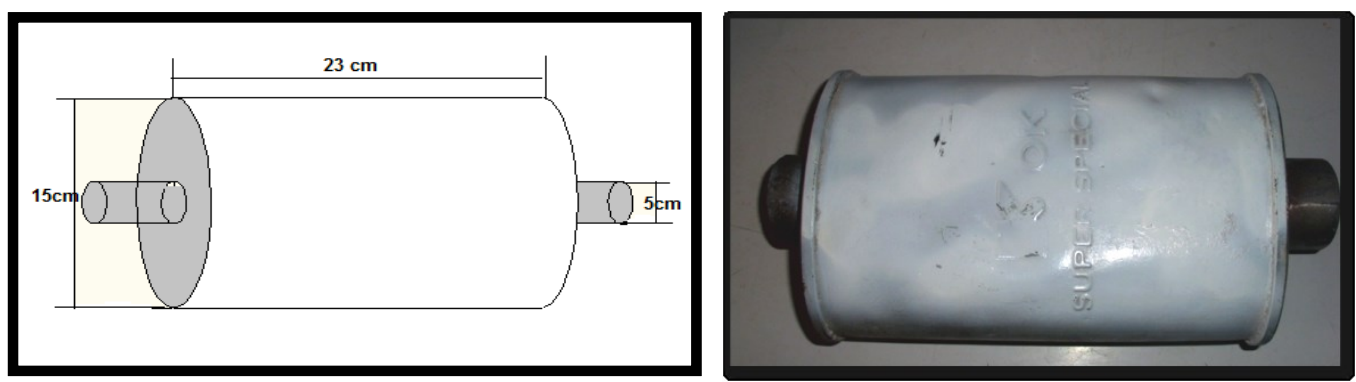

Figure (6): The muffler

The specification of the sound level meter used is RION (weight A, B, and C, SPL (sound pressure level) $=-10-120 \mathrm{~dB}$ ) which connect to the outlet pipe to measure the amount (SPL), as in figure (7).

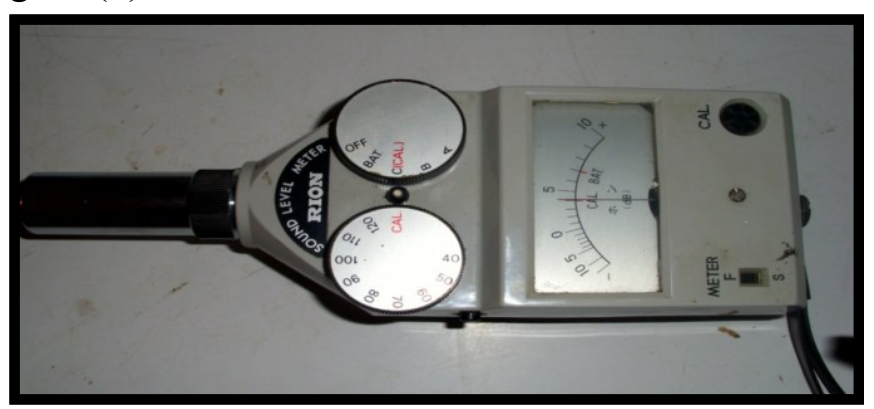

Figure (7): Sound level meter

The function generator, which generates the sound, connects to the amplifier to amplify the waves then connect to the sound speaker (the amplifier and the sound speaker in one device), then connect to the box (duct) which prevents the sound reflect from its path.

In the first, measuring the sound pressure level (SPL) at the excite pipes of the duct by the sound level meter which measure SPL a $(\mathrm{dB})$ unit (we should put the sound level meter at the center of the pipes and fixed it and calibration it by put the represented on the word (cal)), then take the measurement by the controlling of the (dB) scales. 
The following step put the silencer at the end of the excite pipe of duct then take measurement at the exit pipe of the silencer by the same method, this measurement represent (SPL1).

Then take the measurement to the (continuous, corrugate and spiral pipes) that represents SPL2.

Case 1: inlet continuous pipe $(\mathrm{L}=10 \mathrm{~cm})$ connect to the silencer.

Case 2: inlet continuous pipe $(\mathrm{L}=20 \mathrm{~cm})$ connect to the silencer.

Case 3: inlet continuous pipe $(\mathrm{L}=30 \mathrm{~cm})$ connect to the silencer.

Case 4: outlet continuous pipe $(\mathrm{L}=10 \mathrm{~cm})$ connect to the silencer.

Case 5: outlet continuous pipe $(\mathrm{L}=20 \mathrm{~cm})$ connect to the silencer.

Case 6: outlet continuous pipe $(\mathrm{L}=30 \mathrm{~cm})$ connect to the silencer.

Case 7: inlet and outlet continuous pipe $(\mathrm{L}=10 \mathrm{~cm})$ connect to the silencer.

Case 8: inlet and outlet continuous pipe $(\mathrm{L}=20 \mathrm{~cm})$ connect to the silencer.

Case 9: inlet and outlet continuous pipe $(\mathrm{L}=30 \mathrm{~cm})$ connect to the silencer.

Case 10: inlet corrugate pipe $(\mathrm{L}=30 \mathrm{~cm})$ connect to the silencer.

Case 11: inlet corrugate pipe $(\mathrm{L}=50 \mathrm{~cm})$ connect to the silencer.

Case 12: inlet corrugate pipe $(\mathrm{L}=70 \mathrm{~cm})$ connect to the silencer.

Case 13: outlet corrugate pipe $(\mathrm{L}=30 \mathrm{~cm})$ connect to the silencer.

Case 14: outlet corrugate pipe $(\mathrm{L}=50 \mathrm{~cm})$ connect to the silencer.

Case 15: outlet corrugate pipe $(\mathrm{L}=70 \mathrm{~cm})$ connect to the silencer.

Case 16: inlet and outlet corrugate pipe $(\mathrm{L}=30 \mathrm{~cm})$ connect to the silencer.

Case 17: inlet and outlet corrugate pipe $(\mathrm{L}=50 \mathrm{~cm})$ connect to the silencer.

Case 18: inlet and outlet corrugate pipe $(\mathrm{L}=70 \mathrm{~cm})$ connect to the silencer.

Case 19: inlet spiral pipe $(\mathrm{L}=10 \mathrm{~cm})$ connect to the silencer.

Case 20: inlet spiral pipe $(\mathrm{L}=20 \mathrm{~cm})$ connect to the silencer.

Case 21: inlet spiral pipe $(\mathrm{L}=30 \mathrm{~cm})$ connect to the silencer.

Case 22: outlet spiral pipe $(\mathrm{L}=10 \mathrm{~cm})$ connect to the silencer.

Case 23: outlet spiral pipe $(\mathrm{L}=20 \mathrm{~cm})$ connect to the silencer.

Case 24: outlet spiral pipe $(\mathrm{L}=30 \mathrm{~cm})$ connect to the silencer.

Case 25: inlet and outlet spiral pipe $(\mathrm{L}=10 \mathrm{~cm})$ connect to the silencer.

Case 26: inlet and outlet spiral pipe $(\mathrm{L}=20 \mathrm{~cm})$ connect to the silencer.

Case 27: inlet and outlet spiral pipe $(\mathrm{L}=30 \mathrm{~cm})$ connect to the silencer.

Figure (8) illustrate the method of connection the pipes with other parts. 

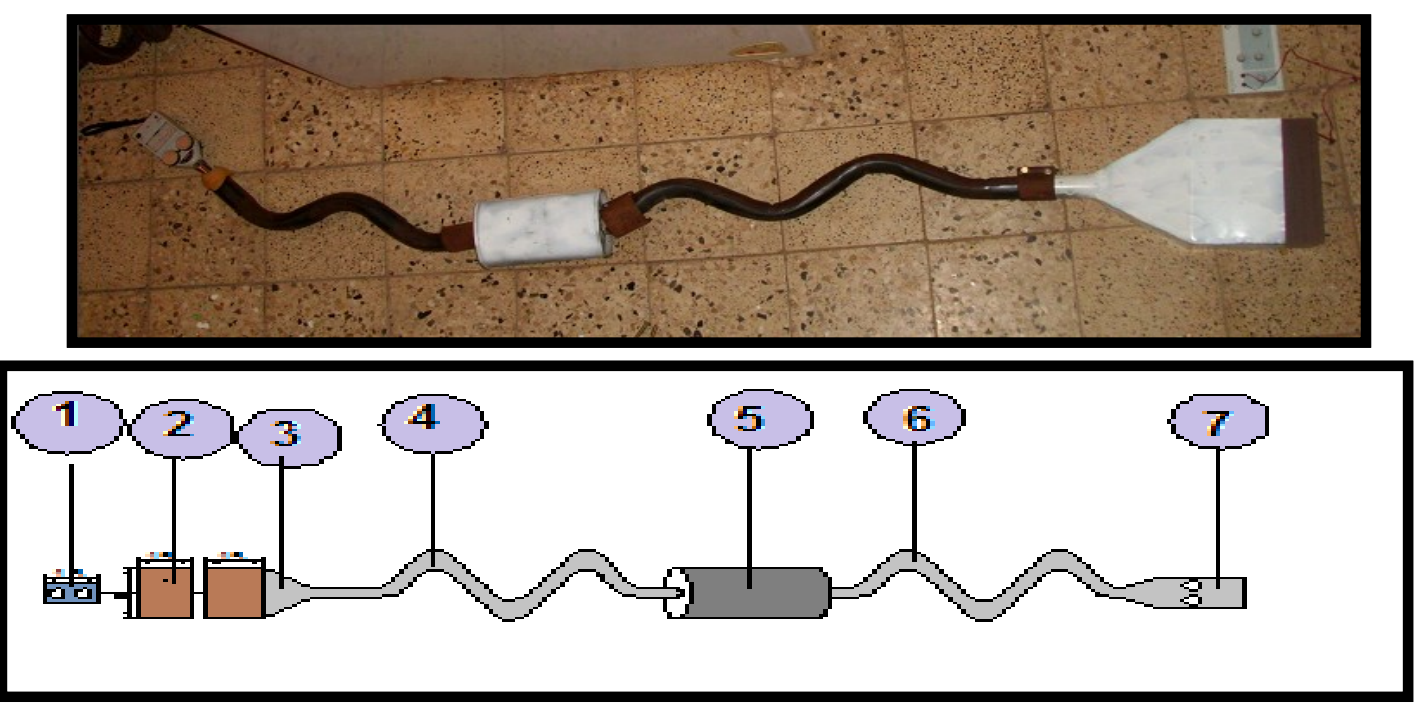

Figure (8): The method of connection.

1- Function Generator. 2- Speaker. 3- Amplifier. 4, 6- Pipes. 5- Silencer. 7- Sound Level Meter.

\section{3- Results and Discussion}

The experimental results contain the calculations to find the values of transmission losses (TL) which equal the difference between SPL1 (sound pressure level) and SPL2, and then find the values of transmission coefficient (Tc) which equal (SPL2/SPL1). Where:

$$
\begin{aligned}
& \mathrm{TL}=\mathrm{SPL} 1-\mathrm{SPL} 2 \\
& \mathrm{Tc}=\frac{\mathrm{SPL} 1}{\mathrm{SPL} 2}
\end{aligned}
$$




\subsection{Transmission Losses}

\subsubsection{Continuous Pipes}

Figure (9) shows the relation between transmission losses (TL) and frequency for inlet, outlet and inlet-outlet continuous pipes.
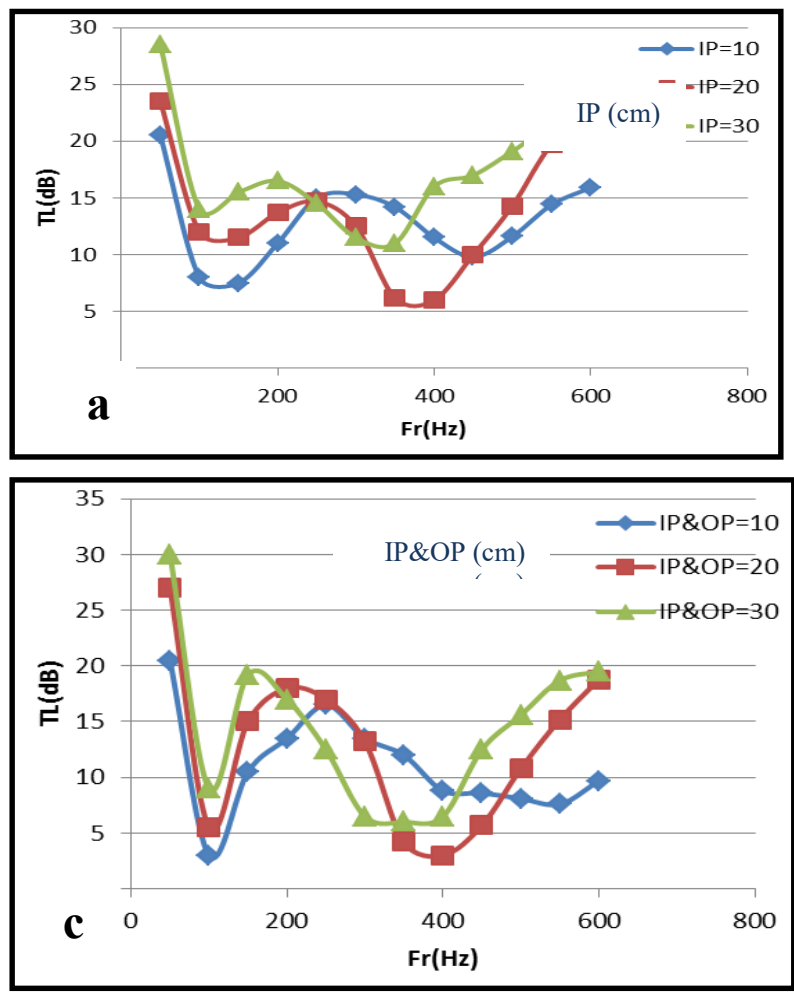

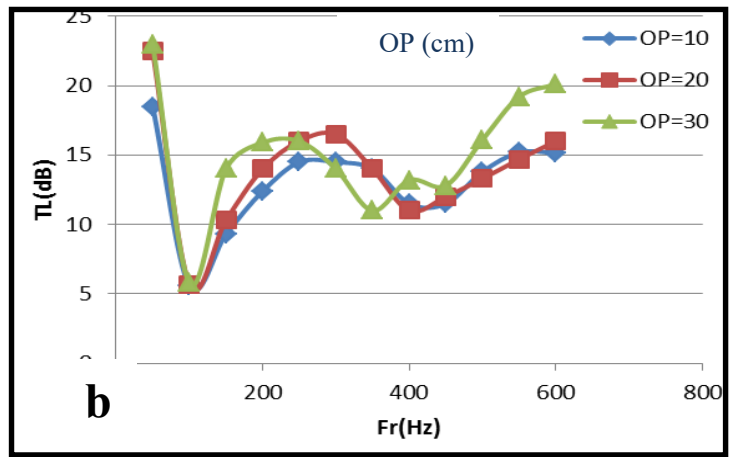

Figure (9): Transmission losses - frequency (continuous pipes)

a- Inlet. b- Outlet. c- Inlet-outlet.

From fig (9-a) at frequency of (50) $\mathrm{Hz}$ the losses have a maximum values of $(20.5,23.5$ and 28.5) $\mathrm{dB}$ for inlet pipe length $(10,20$ and 30$) \mathrm{cm}$ respectively

For $(10 \mathrm{~cm})$ inlet pipe the minimum losses occur at $(150) \mathrm{Hz}$ is $(7.5) \mathrm{dB}$ and for $(20 \mathrm{~cm})$ inlet pipe the minimum losses occur at $(400) \mathrm{Hz}$ is (6) $\mathrm{dB}$ and for $(30 \mathrm{~cm})$ inlet pipe the minimum losses occur at $(350) \mathrm{Hz}$ is $(11) \mathrm{dB}$.

Fig (9-b) illustrates the sound level meter with frequency. At frequency of (50) $\mathrm{Hz}$ the losses have a maximum value of $(18.5,22.5$ and 23$) \mathrm{dB}$ for outlet pipe length $(10,20$ and 30) $\mathrm{cm}$ respectively.

At (100) $\mathrm{Hz}$ the minimum losses values $(5.6,5.7$ and 5.8) $\mathrm{dB}$ for outlet pipe length (10, 20 and 30$) \mathrm{cm}$ respectively.

It can be notice from fig (9-c) the sound level meter with frequency. At frequency of (50) $\mathrm{Hz}$ the losses have a maximum values of $(20.5,27$ and 30) $\mathrm{dB}$ for inlet-outlet pipe length $(10,20$ and 30$) \mathrm{cm}$ respectively. 
For $(10 \mathrm{~cm})$ inlet-outlet pipe the minimum losses occur at $(100) \mathrm{Hz}$ is $(3) \mathrm{dB}$ and for $(20$ $\mathrm{cm}$ ) inlet-outlet pipe the minimum losses occur at (400) $\mathrm{Hz}$ is (3) $\mathrm{dB}$ and for $(30 \mathrm{~cm})$ inlet-outlet pipe the minimum losses occur at (350) $\mathrm{Hz}$ is (6) $\mathrm{dB}$.

\subsubsection{Corrugated Pipes}

Figure (10) presents the sound level meter with frequency for inlet, outlet and inletoutlet for corrugate pipes.
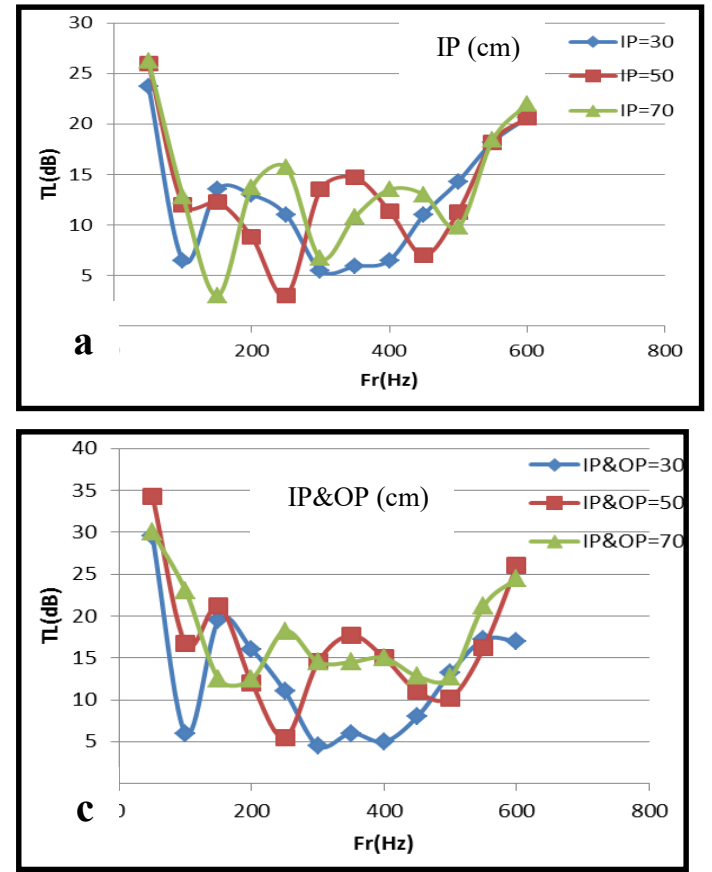

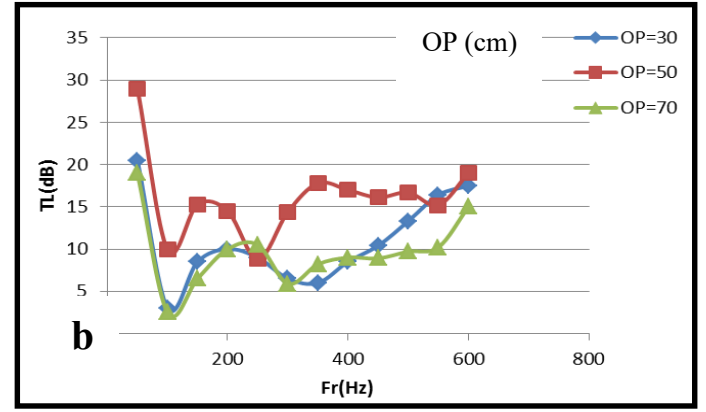

Figure (10): Transmission losses-frequency (corrugate pipes)

a- Inlet. c- Inlet-Outlet

At frequency of (50) $\mathrm{Hz}$ the maximum values of losses (23.7, 26 and 26.2) $\mathrm{dB}$ for inlet pipe length $(30,50$ and 70$) \mathrm{cm}$ respectively as shown in fig (10-a).

For $(30 \mathrm{~cm})$ inlet pipe the minimum losses occur at $(300) \mathrm{Hz}$ is $(5.5) \mathrm{dB}$ and for $(50 \mathrm{~cm})$ inlet pipe the minimum losses occur at $(250) \mathrm{Hz}$ is (3) $\mathrm{dB}$ and for $(70 \mathrm{~cm})$ inlet pipe the minimum losses occur at $(150) \mathrm{Hz}$ is $(3) \mathrm{dB}$.

The maximum values of losses occur at frequency of (50) $\mathrm{Hz}$ are $(20.5,29$ and 19) $\mathrm{dB}$ for outlet pipe length $(30,50$ and 70$) \mathrm{cm}$ respectively illustrate in fig (10-b).

For $(30 \mathrm{~cm})$ outlet pipe the minimum losses occur at $(50) \mathrm{Hz}$ is $(3) \mathrm{dB}$ and for $(50 \mathrm{~cm})$ outlet pipe the minimum losses occur at $(250) \mathrm{Hz}$ is $(8.8) \mathrm{dB}$ and for $(70 \mathrm{~cm})$ outlet pipe the minimum losses occur at (100) $\mathrm{Hz}$ is $(2.5) \mathrm{dB}$.

Fig (10-c) shows that the frequency of (50) $\mathrm{Hz}$ the losses have a maximum value of $(29.5,34.3$ and 30$) \mathrm{dB}$ for inlet-outlet pipe length $(30,50$ and 70$) \mathrm{cm}$ respectively.

For $(30 \mathrm{~cm})$ inlet-outlet pipe the minimum losses occur at $(300) \mathrm{Hz}$ is $(4.5) \mathrm{dB}$ and for $(50 \mathrm{~cm})$ inlet-outlet pipe the minimum losses occur at $(250) \mathrm{Hz}$ is $(5.5) \mathrm{dB}$ and for $(70$ $\mathrm{cm})$ inlet-outlet pipe the minimum losses occur at $(150 \& 200) \mathrm{Hz}$ is $(12.5) \mathrm{dB}$. 


\subsubsection{Spiral Pipes}

Figure (11-a) present the variation of the transmission losses with frequency. It can be notice that the frequency of $(600) \mathrm{Hz}$ the losses have a maximum value of (20.9) $\mathrm{dB}$ for $(10 \mathrm{~cm})$ inlet pipe length and at $(50) \mathrm{Hz}(27.5) \mathrm{dB}$ for $(20 \mathrm{~cm})$ inlet pipe length and at $(50) \mathrm{Hz}(27.5) \mathrm{dB}$ for $(30 \mathrm{~cm})$ inlet pipe length.

For $(10 \mathrm{~cm})$ inlet pipe the minimum losses occur at $(150) \mathrm{Hz}$ is $(8.5) \mathrm{dB}$ and for $(20 \mathrm{~cm})$ inlet pipe the minimum losses occur at $(100) \mathrm{Hz}$ is $(7.5) \mathrm{dB}$ and for $(30 \mathrm{~cm})$ inlet pipe the minimum losses occur at (150) $\mathrm{Hz}$ is (3.5) dB.

From figure (11-b) it can be seen that the frequency of (50) $\mathrm{Hz}$ the losses have a maximum value of $(16.5) \mathrm{dB}$ for $(10 \mathrm{~cm})$ outlet pipe length and at (50) $\mathrm{Hz}(20.5) \mathrm{dB}$ for $(20 \mathrm{~cm})$ outlet pipe length and at $(50) \mathrm{Hz}(26) \mathrm{dB}$ for $(30 \mathrm{~cm})$ outlet pipe length.

For $(10 \mathrm{~cm})$ outlet pipe the minimum losses occur at $(150) \mathrm{Hz}$ is $(3.3) \mathrm{dB}$ and for $(20$ $\mathrm{cm}$ ) outlet pipe the minimum losses occur at $(100) \mathrm{Hz}$ is $(2) \mathrm{dB}$ and for $(30 \mathrm{~cm})$ outlet pipe the minimum losses occur at $(100) \mathrm{Hz}$ is (4.8) $\mathrm{dB}$.

While figure (11-c) shows that the frequency of (600) $\mathrm{Hz}$ the losses have a maximum value of (18.5) dB for $(10 \mathrm{~cm})$ inlet-outlet pipe length and at $(50) \mathrm{Hz}(24) \mathrm{dB}$ for $(20$ $\mathrm{cm})$ inlet-outlet pipe length and at $(50) \mathrm{Hz}(28) \mathrm{dB}$ for $(30 \mathrm{~cm})$ inlet-outlet pipe length.

For $(10 \mathrm{~cm})$ inlet-outlet pipe the minimum losses occur at $(400) \mathrm{Hz}$ is $(4) \mathrm{dB}$ and for $(20$ $\mathrm{cm}$ ) inlet-outlet pipe the minimum losses occur at (400) $\mathrm{Hz}$ is (1) $\mathrm{dB}$ and for $(30 \mathrm{~cm})$ inlet-outlet pipe the minimum losses occur at (100) $\mathrm{Hz}$ is (4) $\mathrm{dB}$
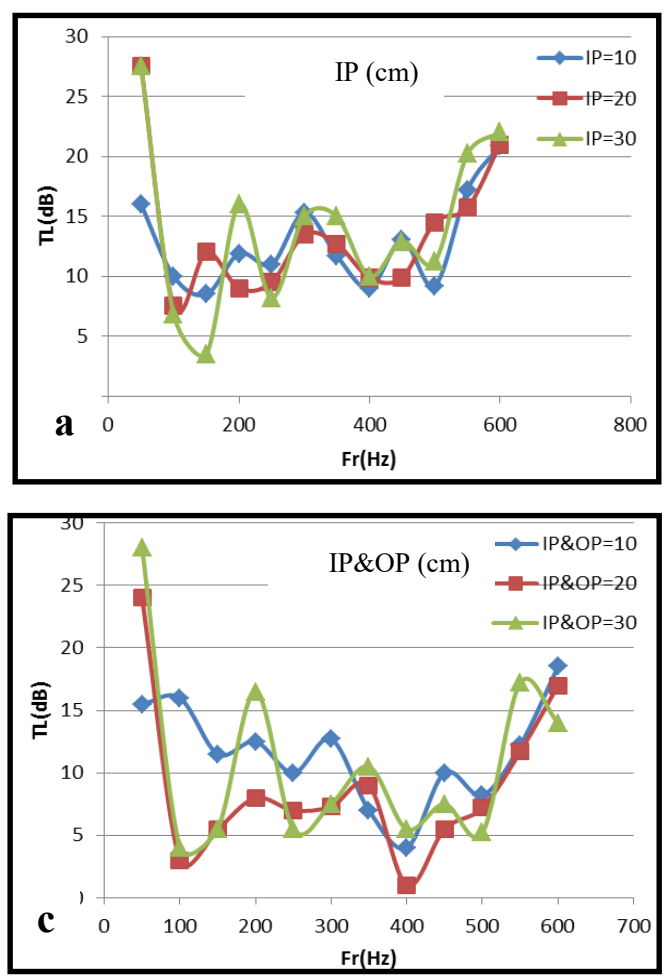

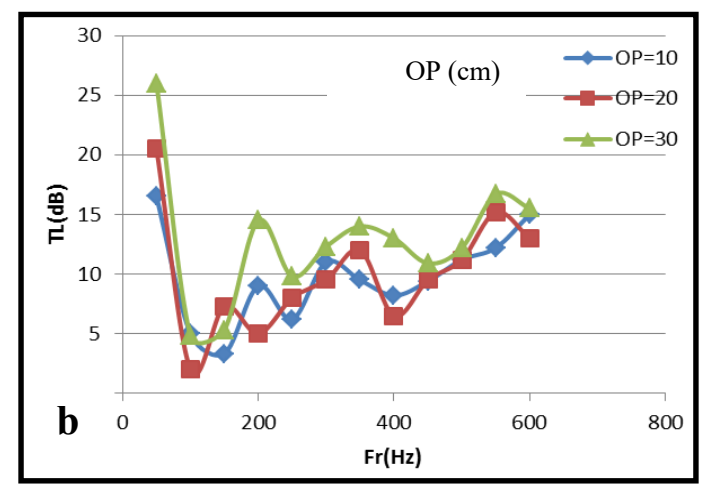

Figure (11): Transmission losses-frequency (spiral pipes)
a- Inlet.
b- Outlet.
c- Inlet-Outlet. 


\subsection{Transmission Coefficient}

\subsubsection{Continuous Pipes}

The transmission coefficient vs. frequency is plotted for the continuous pipes as shown in figure (12).

It was observed from fig (12-a) that the frequency of $(150) \mathrm{Hz}$ the transmission coefficient have a maximum value of $(0.937)$ for $(10 \mathrm{~cm})$ inlet pipe length and at $(400)$ $\mathrm{Hz}(0.942)$ for $(20 \mathrm{~cm})$ inlet pipe length and at $(350) \mathrm{Hz}(0.895)$ for $(30 \mathrm{~cm})$ inlet pipe length.

For $(10 \mathrm{~cm})$ inlet pipe the minimum transmission coefficient occur at $(50) \mathrm{Hz}$ is $(0.820)$ and for (20) inlet pipe the minimum transmission coefficient occur at (60) $\mathrm{Hz}$ is $(0.792)$ and for $(30 \mathrm{~cm})$ inlet pipe the minimum transmission coefficient occur at $(50) \mathrm{Hz}$ is (0.751).

Based on fig (12-b) the frequency of $(100) \mathrm{Hz}$, the transmission coefficient have a maximum values of $(0.950,0.95$ and 0.949$)$ for outlet pipe length $(10,20$ and 30$) \mathrm{cm}$ respectively.

For (10, 20 and 30) cm outlet pipe length the minimum transmission coefficient occur at (50) $\mathrm{Hz}$ are $(0.838,0.803$ and 0.799$)$ respectively.

It can be seen from fig (12-c) that the frequency of (100) $\mathrm{Hz}$ the transmission coefficient have a maximum value of $(0.973)$ for $(10 \mathrm{~cm})$ inlet-outlet pipe length and at $(400) \mathrm{Hz}$ $(0.971)$ for $(20 \mathrm{~cm})$ inlet-outlet pipe length and at $(350) \mathrm{Hz}(0.942)$ for $(30 \mathrm{~cm})$ inletoutlet pipe length.

For $(10,20$ and 30) $\mathrm{cm}$ inlet-outlet pipe the minimum transmission coefficient occur at (50) $\mathrm{Hz}$ are $(0.82,0.767$ and 0.737$)$ respectively.

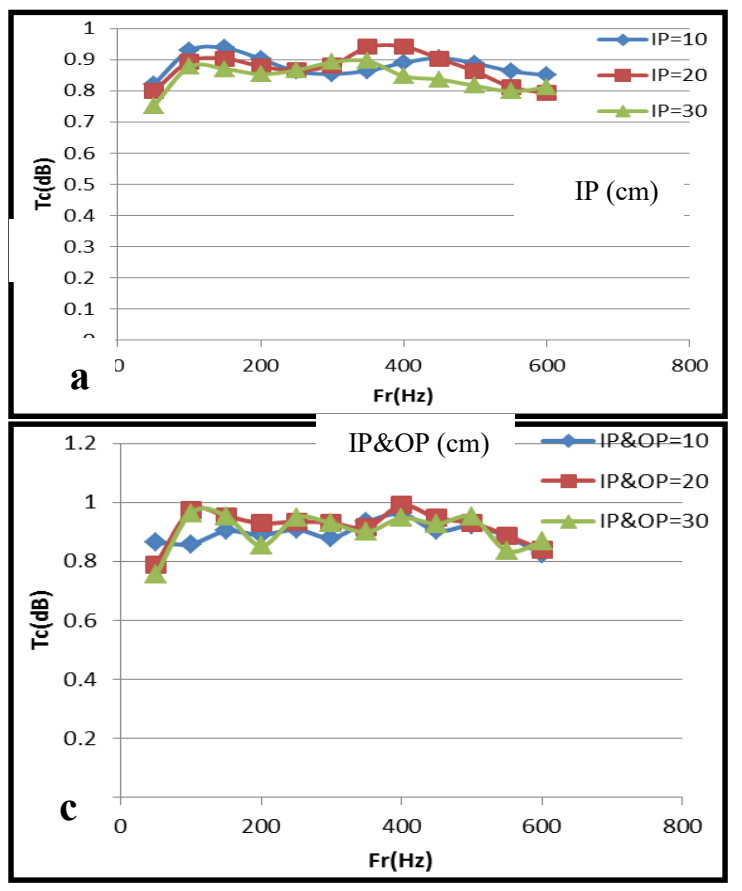

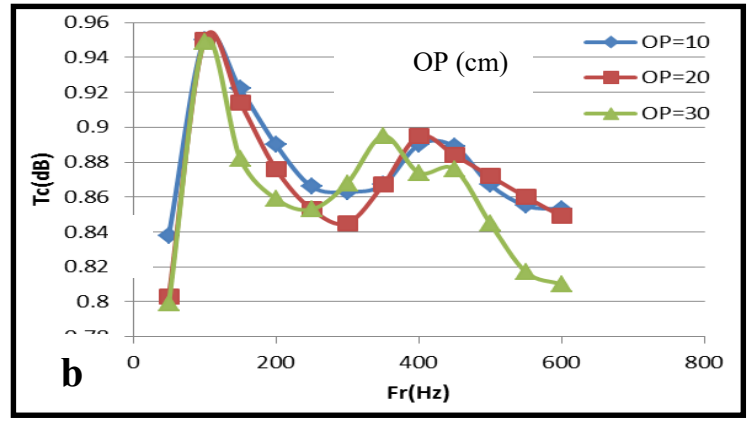

Figure (12): Transmission coefficient -frequency (continuous pipes)

a- Inlet. b- Outlet. c- Inlet-Outlet 


\subsubsection{Corrugate Pipes}

The transmission coefficient vs. frequency is plotted for the corrugate pipes as shown in figure (13).
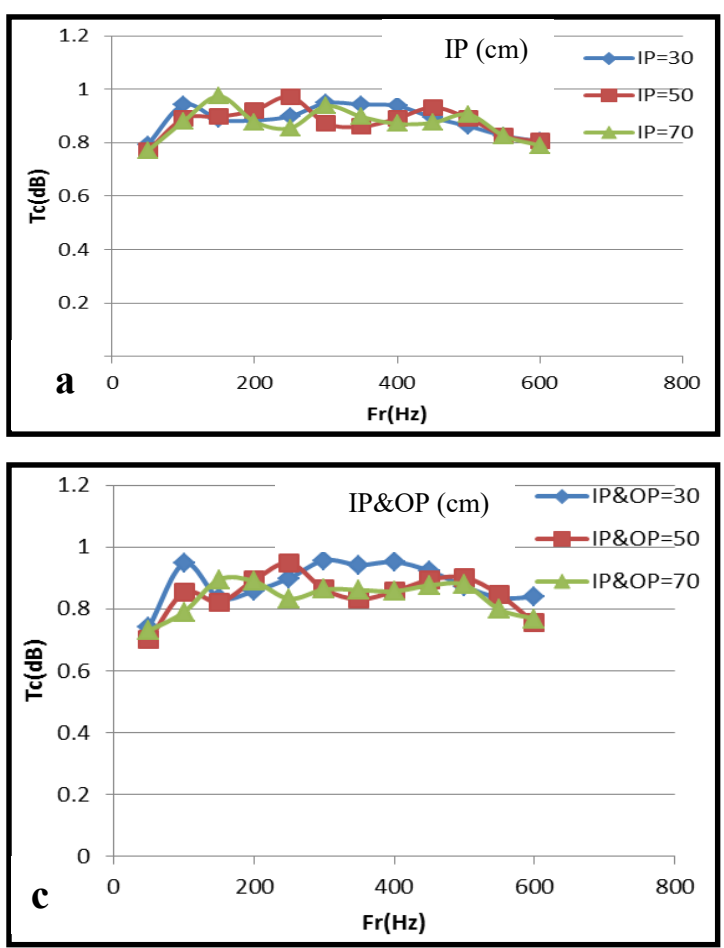

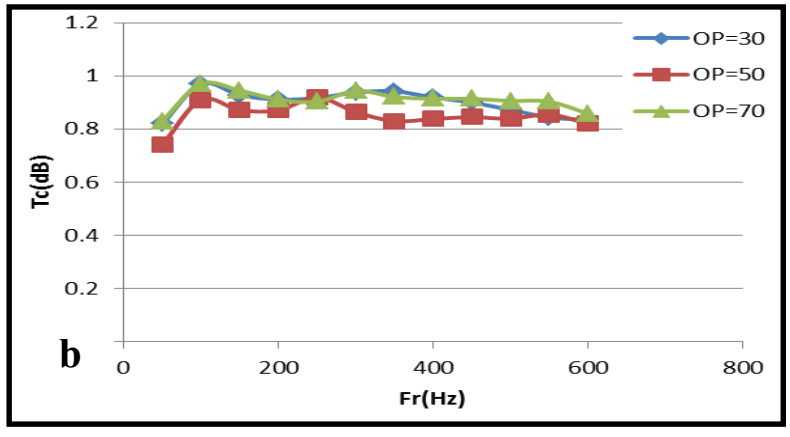

Figure (13): Transmission coefficient frequency (Corrugate pipes) a- Inlet. b- Outlet. c- InletOutlet.

Fig (13-a) represents the transmission coefficient with frequency. At frequency of (300) $\mathrm{Hz}$ the transmission coefficient have a maximum value of $(0.948)$ for $(30 \mathrm{~cm})$ inlet pipe length and at $(250) \mathrm{Hz}(0.972)$ for $(50 \mathrm{~cm})$ inlet pipe length and at $(150) \mathrm{Hz}$ $(0.974)$ for $(70 \mathrm{~cm})$ inlet pipe length.

For $(30,50$ and 70$) \mathrm{cm}$ inlet pipe the minimum transmission coefficient values occur at (50) $\mathrm{Hz}$ are $(0.793,0.77$ and 0.77$)$ respectively.

Fig (13-b) show that the transmission coefficient with frequency. At frequency of (100) $\mathrm{Hz}$ the transmission coefficient have a maximum value of $(0.97)$ for $(30 \mathrm{~cm})$ outlet pipe length and at $(250) \mathrm{Hz}(0.919)$ for $(50 \mathrm{~cm})$ outlet pipe length and at $(100) \mathrm{Hz}(0.970)$ for $(70 \mathrm{~cm})$ outlet pipe length.

For (30, 50 and 70$) \mathrm{cm}$ outlet pipe the minimum transmission coefficient values occurs at $(50) \mathrm{Hz}$ are $(0.82,0.74$ and 0.830$)$ respectively.

It can be seen from fig (13-c) that the frequency of (300) Hz the transmission coefficient have a maximum value of $(0.957)$ for $(30 \mathrm{~cm})$ inlet-outlet pipe length and at $(250) \mathrm{Hz}$ $(0.949)$ for $(50 \mathrm{~cm})$ inlet-outlet pipe length and at $(150) \mathrm{Hz}(0.895)$ for $(70 \mathrm{~cm})$ inletoutlet pipe length.

While the minimum transmission coefficient values occur at $(50) \mathrm{Hz}$ is $(0.742,0.700$ and 0.73 ) for inlet-out let pipe length $(30,50$ and 70$) \mathrm{cm}$ respectively. 


\subsubsection{Spiral Pipes}

Figure (14) clarify the relation between transmission coefficients with frequency.
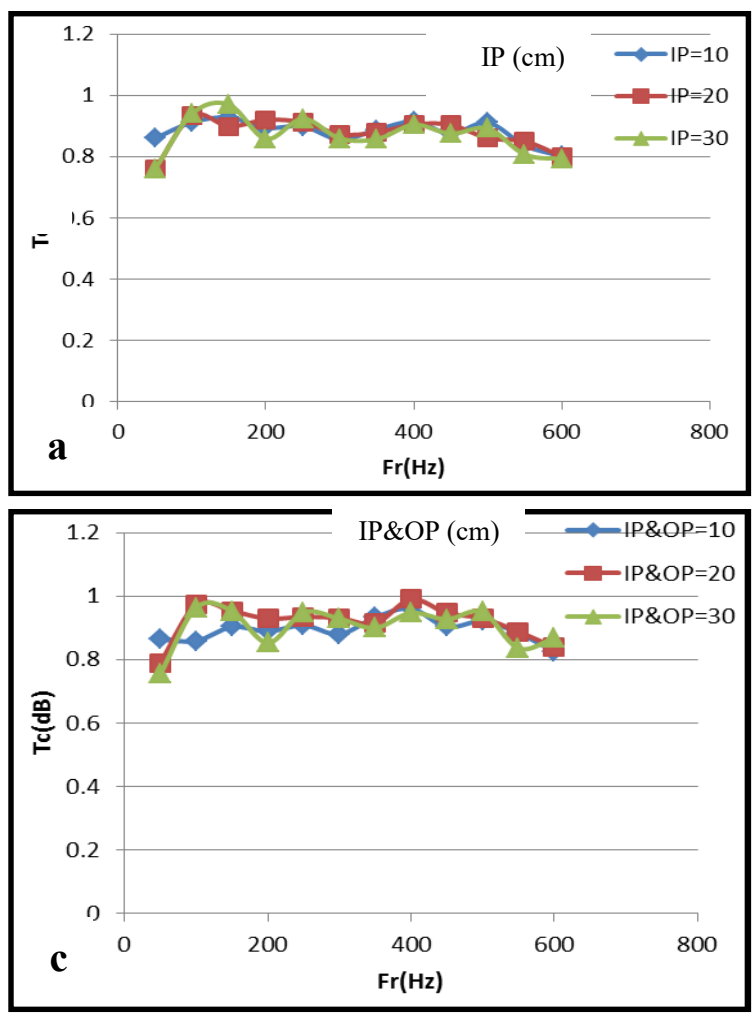

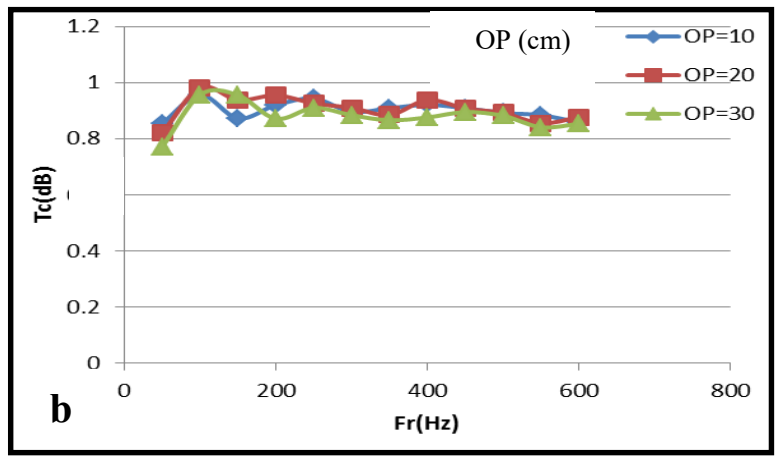

Figure (14): Transmission coefficient frequency (spiral pipes)

a-Inlet. b- Outlet. c- Inlet-Outlet.

Fig (14-a) represents the transmission coefficient with frequency. At frequency of (150) $\mathrm{Hz}$ the transmission coefficient have a maximum value of $(0.928)$ for $(10 \mathrm{~cm})$ inlet pipe length and at $(100) \mathrm{Hz}(0.934)$ for $(20 \mathrm{~cm})$ inlet pipe length and at $(150) \mathrm{Hz}$ $(0.970)$ for $(30 \mathrm{~cm})$ inlet pipe length. For $(10 \mathrm{~cm})$ inlet pipe the minimum transmission coefficient occur at $(600) \mathrm{Hz}$ is $(0.802)$ and for $(20 \mathrm{~cm})$ inlet pipe the minimum transmission coefficient occur at $(50) \mathrm{Hz}$ is $(0.759)$ and for $(30 \mathrm{~cm})$ inlet pipe the minimum transmission coefficient occur at (50) Hz is (0.759). Fig (14-b) shows the transmission coefficient with frequency. At frequency of (150) $\mathrm{Hz}$ the transmission coefficient have a maximum value of $(0.972)$ for $(10 \mathrm{~cm})$ outlet pipe length and at (100) $\mathrm{Hz}(0.982)$ for $(20 \mathrm{~cm})$ outlet pipe length and at $(100) \mathrm{Hz}(0.957)$ for $(30 \mathrm{~cm})$ outlet pipe length. For $(10,20$ and 30$) \mathrm{cm}$ outlet pipe the minimum transmission coefficient values occurs at $(50) \mathrm{Hz}$ are $(0.855,0.820$ and 0.772$)$ respectively. While fig (14-c) represents the transmission coefficients with frequency.

At frequency of $(400) \mathrm{Hz}$ the transmission coefficient have a maximum value of $(0.961)$ for $(10 \mathrm{~cm})$ inlet-outlet pipe length and at $(400) \mathrm{Hz}(0.990)$ for $(20 \mathrm{~cm})$ inletoutlet pipe length and at $(100) \mathrm{Hz}(0.964)$ for $(30 \mathrm{~cm})$ inlet-outlet pipe length. For $(10$ 
$\mathrm{cm})$ inlet-outlet pipe the minimum transmission coefficient occur at $(600) \mathrm{Hz}$ is $(0.825)$ and for $(20 \mathrm{~cm})$ inlet-outlet pipe the minimum transmission coefficient occur at $(50) \mathrm{Hz}$ is $(0.790)$ and for $(30 \mathrm{~cm})$ inlet-outlet pipe the minimum transmission coefficient occur at $(50) \mathrm{Hz}$ is $(0.755)$. It is clear that the silencers when installed in the exhaust pipe, it becomes impediment to sound waves transmitted. The shape of the pipe associated with identifying the natural frequency of vibration as well as the value of the speed of sound affect this frequency for different locations. Thus, the vibration characteristics are different from one location to another, as is evident through the search results. It was observed that the increasing of the pipe length affect significantly on the vibration values in all of the cases that have been studied, because of a change in natural frequencies as a result of increased area, which is the path for the transmission of sound waves, This leads to the exposure of the surface of the pipe to more vibrations. It is worth mentioning that the absence of damping in the system definitely leads to higher values vibrational amplitudes.

\section{Conclusion}

Experimental results showed that the different shapes and lengths of the inlet and outlet pipes can reduce the noise. Also it can be seen that the corrugated pipe $(\mathrm{L}=50 \mathrm{~cm}$ and $\mathrm{d}=4.8 \mathrm{~cm})$ is preferred, because it is reduced the noise about $(\mathrm{TL}=34.3 \mathrm{~dB})$ and $(\mathrm{Tc}=0.949)$. This type of pipes contain areas impede the movement of sound waves for appropriate distances and this effects on the natural frequencies, thus the transmission of vibration on the surface of the pipe have been affected compared with the other shapes that have been studied thus the application can be used in automobiles, large or small generators, motors, turbines and other requirements. 


\section{Refferances}

[1] Bulletin OZ3000, 2005, "Noise Control Manual".

[2] Beranek L. L. and Ver, I. L., 1992," Noise and Vibration Control Engineering”, Principle and Application, $2^{\text {nd }}$ edition, John Wiley \& Sons Inc.

[3] Kassim M. S., Al-Doory M. K. and Al-Ameen E. S., June 2012, "Experimental Investigation for the effect of Inlet \& Outlet Pipe Lengths on Noise Attenuation in a Muffler", Journal of Engineering and Development, Vol. 16, No.2, ISSN 18137822.

[4] Kassim M. K., 2013, "Investigation the Effect of the Reactive Muffler Connections on Noise Attenuation", AL-Qadisiya Jou rnal For Engineering Sciences, Vol. 6.No. 2.

[5] Jian-dawu and Mingsian Bai, 2003, "A ring Silencer for reducing noise of axial fan" Fluctuation and noise letters, Vol. (3), Issue (03).

[6] M. Ali T. and Y.G. Awaad, 2010, "Vibration analysis of exhaust gas silencer" , Magazine of Engineering and Technology, Vol. (28), Issue (16), P.P. (772-797).

[7] Ya-wei Zhu, Fa-wang Zhu, Yan-shan Zhang and Qing-guo Wei, 2017, "The research on semi-active muffler device of controlling the exhaust pipe's lowfrequency noise", Journal of Applied Acoustics 116, p.p. (9-13).

[8] T.Ichiyangi, 2001, "Reducing the Fluid-Borne Noise in Fluid Power Systems, Department of Mechanical Systems Engineering, National Defense Academy", Japan, Jean-charles Mare.

[9] Sumit Surve, Suraj Kumbhar and S. S. Goilkar, 2014, "Acoustics and Flow Field Analysis of Perforated Muffler Design", International Journal of Engineering Development and Research (www.ijedr.org), Vol. (2), Issue (4). 